\title{
Desponte e embebição em sementes de noni (Morinda citrifolia L.)
}

\author{
OLIVEIRA,K.P'; BATISTA,D.S'; SOUZA,D.C.F'; BENEDITO,C.P'; RIBEIRO,M.C.C'. \\ ${ }^{1}$ UFERSA-Universidade Federal Rural do Semi-Árido. Mossoró 59625-900, RN-Brasil. kellypatricia85@hotmail.com
}

\begin{abstract}
RESUMO: O trabalho teve como objetivo testar a germinação em sementes de noni sob diferentes tempos de embebição, com e sem o desponte das sementes. Para isso, instalou-se um experimento em casa de vegetação no delineamento inteiramente casualizado com 10 tratamentos e 4 repetições de 25 sementes, sendo constituídos por: 1 . Testemunha; 2 . Sementes com desponte do lado oposto ao embrião; 3. Sementes intactas com 12 horas de embebição; 4. Sementes intactas com 24 horas de embebição; 5 . Sementes intactas com 36 horas de embebição; 6. Sementes intactas com 48 horas de embebição; 7. Sementes com desponte com 12 horas de embebição; 8. Sementes com desponte com 24 horas de embebição; 9 . Sementes com desponte com 36 horas de embebição e 10. Sementes com desponte com 48 horas de embebição. As características avaliadas foram: porcentagem de emergência, Índice de velocidade de emergência, altura de plântulas, comprimento de raiz e peso de massa seca das plântulas aos 46 dias após a instalação do experimento. Houve diferença significativa entre os diferentes tempos de embebição e o tratamento 10 (Desponte com 48 hs de embebição) que obteve os melhores resultados para a percentagem de emergência, índice e velocidade de emergência e peso seco. Quanto a altura de plântula, o tratamento 1 (Testemunha) foi o maior, enquanto no tratamento 2 (desponte) se verificou o maior comprimento de raiz. Embora não tenha diferido da testemunha, o melhor tratamento foi o uso do desponte +48 horas de embebição.
\end{abstract}

Palavras-chave: Morinda citrifolia, sementes, emergência.

ABSTRACT: Lopping and soaking in seeds of noni (Morinda citrifolia L.). The study aimed to test the germination of seeds of noni under different soaking times, with and without the seed emerges. For this, an experiment was installed in a greenhouse in a completely randomized design with 10 treatments and 4 replicates of 25 seeds, being composed of: 1 . Witness 2 . Seeds with the blunt side opposite the embryo 3 . Intact seeds with 12 hours of soaking, 4. Intact seeds with 24 hours of soaking, 5 . Intact seeds with 36 hours of soaking, 6 . Intact seeds with 48 hours of soaking; 7 . Seeds with cutting with 12 hours of soaking; 8 . Seeds with cutting with 24 hours of soaking; 9 . Seeds with cutting with 36 hours of soaking and 10 . Seeds with cutting with 48 hours of soaking. The characteristics evaluated were: percentage of emergence, speed of emergence index, seedling height, root length and weight of the dry mass of seedlings 46 days after the experiment. There were significant differences between the different times of soaking and treatment 10 (cutting with 48 hours of soaking) who obtained the best results for the percentage of emergency and emergency speed index and dry weight. The height of the seedling, one treatment (control) was the highest, while in treatment 2 (blunt) registered the largest root length. Although the witness did not differ, the best treatment was the use of blunt +48 hours of soaking.

Key words: Morinda citrifolia, seeds, emergency.

\section{INTRODUÇÃO}

Morinda cirtrifolia pertence à família Rubiaceae tem ampla diversidade e ocorre nos mais diversos tipos de ambiente. É um arbusto que pode medir de 3 a 6 metros de altura, de acordo com Germosén \& Robineau (1995). É uma planta bastante precoce e após ter iniciado a fase de produção de frutos ela se torna constante, produzindo o ano inteiro, segundo Xangai (2007). Praticamente todas as partes da planta de noni são utilizadas e a cada uma delas são atribuídas propriedades medicinais diferentes. $\mathrm{O}$ fruto é a parte da planta de mais ampla utilização, sendo várias as aplicações, entre estas:

Recebido para publicação: agosto de 2011

Aceito para publicação: dezembro de 2011

Rev. Bras. PI. Med., Botucatu, v.13, especial, p.513-517, 2011. 
antibactericida, analgésico, anticongestivo, antioxidante, expectorante, antiinflamatório, adstringente, emoliente, emenagogo, laxativo, analgésico, hipotensor, purificador do sangue, imunoestimulante e tônico, segundo Elkins (1997). Também é atribuída ao fruto, ação anticancerígena, de acordo com Rodríguez \& Pinedo (2005).

A planta apresenta flores e frutos durante todo o ano, sendo as flores pequenas e brancas; os frutos contêm muitas sementes, e tem um forte odor, quando colhida. O fruto é oval e atinge 4 a $7 \mathrm{~cm}$ de tamanho, sendo inicialmente verde, mudando para amarelo e por fim, quase branco, época em que o fruto é colhido segundo Brito (2008).

No Brasil ainda são poucos os trabalhos de pesquisa desenvolvidos com o noni, apesar do grande sucesso e demanda internacional pelos produtos dessa espécie principalmente o suco dos frutos, sendo escassas as informações referentes às características agronômicas, tais como: o meio mais adequado de propagação, as características fisiológicas da germinação e as condições de armazenamento das sementes.

A germinação envolve um conjunto de processos fisiológicos e é influenciada por fatores externos e internos às sementes, podendo agir isoladamente ou interagir entre si (Carvalho \& Nakagawa, 2000). A germinação, sob ponto de vista fisiológico, engloba quatro fases: embebição de água, alongamento das células, divisão celular e diferenciação das células em tecidos de acordo com Popinigis (1985). Durante a embebição, as sementes passam pelas fases preparatórias essenciais à germinação (Fanti \& Perez, 2003).

Os efeitos provocados pela embebição permitem que as sementes atinjam um determinado grau de umidade que ative o sistema metabólico relacionado com o processo pré-germinativo e com a elevação da respiração das células embrionárias Heydecker et al. (1973). Os tratamentos de hidratação parcial das sementes têm sido utilizados para diferentes fins entre os quais estão: a) condicionamento das sementes para recuperar a viabilidade e incrementar a longevidade durante o armazenamento; b) condicionamento para incrementar, acelerar e uniformizar a germinação; c) condicionamento para eliminar dormência ou latência e d) condicionamento das sementes para incrementar a germinação e estabelecimento das plântulas sob condições ambientais adversas (Henckel, 1982; Heydecker et al., 1975; Khan et al., 1978).

Devido às sementes de noni apresentarem demora para iniciar o processo germinativo, o trabalho tem como objetivo testar diferentes tempos de embebição e desponte em parte das sementes para acelerar a emergência de plântulas desta espécie.

\section{MATERIAL E MÉTODO}

Sementes de noni (Morinda citrifolia L.) foram retiradas de frutos maduros, coletados de plantas adultas na Universidade Federal Rural do Semi-Árido no dia 05 de julho de 2010 no município de Mossoró$\mathrm{RN}$. Após a colheita dos frutos foi realizado o beneficiamento das sementes: os frutos foram abertos e as sementes retiradas, logo depois, estas passaram por um processo de lavagem para que fosse retirado todo o excesso de mucilagem. Em seguida, as sementes foram colocadas sobre jornais para a secagem. O experimento foi realizado em casa de vegetação do Departamento de Ciências Vegetais na Universidade Federal Rural do Semi-Árido, situada no município de Mossoró - RN no período de 13 de agosto a 10 de Setembro de 2010. As condições anuais e localização do ensaio são: coordenadas geográficas $5^{\circ} 11^{\prime}$ latitude sul e $37^{\circ} 20^{\prime}$ longitude W. Gr., e $18 \mathrm{~m}$ de altitude, temperatura média anual de $27,5^{\circ} \mathrm{C}$, umidade relativa de $68,9 \%$, nebulosidade média anual de 4,4 décimos e precipitação média anual de $673,9 \mathrm{~mm}$, com clima quente e seco, localizada na região semi-árida do Nordeste brasileiro, Carmo Filho et al. (1987). Os tratamentos prégerminativos foram: testemunha (sementes intactas); sementes com desponte no lado oposto ao embrião realizado com o auxílio de uma tesoura; sementes intactas com 12 horas de embebição; sementes intactas com 24 horas de embebição; sementes intactas com 36 horas de embebição; sementes intactas com 48 horas de embebição; sementes com desponte e 12 horas de embebição; sementes com desponte e 24 horas de embebição; sementes com desponte e 36 horas de embebição; sementes com desponte e 48 horas de embebição. Após o tratamento pré-germinativo, as sementes foram colocadas para germinar em bandejas plásticas com as seguintes dimensões $41 \times 27,5 \times 3,5 \mathrm{~cm}$ de comprimento, largura e profundidade respectivamente. $O$ substrato utilizado foi a vermiculita, previamente umedecida com água, mantendo-se a umidade durante o ensaio. , As sementes foram colocadas para germinar à uma profundidade de duas vezes o tamanho da semente, aproximadamente $2 \mathrm{~cm}$. As características avaliadas foram: porcentagem de emergência (\%E), Índice de velocidade de emergência (IVE), altura de plântulas (AP), comprimento de raiz (CR) e peso de massa seca (PMS) das plântulas. A emergência foi avaliada diariamente, após a primeira emergência (18ํ dia após a semeadura) ate à última (46ํํ dia após a semeadura). Avaliou-se o percentual de emergência tomando-se como base a emergência da plântula no substrato. $O$ IVE foi determinado pelo somatório do número de plântulas normais emergidas a cada dia, dividido pelo número de dias decorridos entre a semeadura e a emergência, conforme Maguire (1962). A medida da altura das plântulas foi feita com auxílio de uma

Rev. Bras. Pl. Med., Botucatu, v.13, especial, p.513-517, 2011. 
régua graduada em centímetros, medindo-se desde a inserção do colo até o ponto de inserção da gema apical. O valor da altura média de plântulas foi obtido pela média aritmética do número de plântulas emergidas em cada repetição. Previamente, as raízes foram imersas em um recipiente com água para facilitar a retirada dos restos dos substratos aderidos à mesma. $O$ comprimento das raízes foi obtido com auxílio de uma régua graduada, onde estas foram medidas desde a inserção do colo até o final da raiz, sendo expressos em centímetros $(\mathrm{cm})$. As plântulas mensuradas de cada repetição foram colocadas em sacos de papel e postas para secar em estufa regulada à $65^{\circ} \mathrm{C}$ até obter massa constante. A massa obtida em cada tratamento foi dividida pelo número de plântulas componentes resultando na massa da matéria seca de plântulas, com resultados expressos em $\mathrm{g} / \mathrm{plântula.} O$ delineamento experimental utilizado foi o inteiramente casualizado com 10 tratamentos e 4 repetições de 25 sementes. Os dados obtidos foram submetidos à análise de variância e as médias comparadas pelo teste de tukey, ao nível de $5 \%$ de probabilidade. O programa estatístico utilizado foi o SISVAR 2 Ferreira (2000). A espécie estudada tem por nome científico, Morinda citrifolia L., cuja excicata está depositada no herbário Dárdano de Andrade Lima - Mossoró sob número MOSS 13603.

\section{RESULTADO E DISCUSSÃO}

De acordo com a análise de variância houve efeito significativo para porcentagem de emergência (\%E), índice e velocidade de emergência (IVE), altura de plântulas (AP), comprimento de raiz (CR), e peso da massa seca (PMS) (Tabela 1).

As médias encontradas para os parâmetros avaliados, em cada tratamento podem ser observadas na Tabela 2.
Com relação à porcentagem de emergência (E\%) o tratamento em que as sementes foram submetidas à embebição por 48 horas e no qual se realizou o desponte no lado oposto ao embrião, obteve maior resultado com $76 \%$ de emergência, diferindo estatisticamente apenas do tratamento sementes intactas + 24 horas de embebição (Figura 1). Diferente de Matos et al. (2003) trabalhando com quebra de dormência em sementes de Saputi (Achras sapota L.) a imersão em água a $60^{\circ} \mathrm{C}$ até resfriamento e a escarificação com lixa $n^{\circ} 100$, seguida de embebição em água por 24 horas, apresentaram maiores percentagens de emergência (72\%), embora não tenham diferido estatisticamente da testemunha (68\%).

No índice e velocidade de emergência (IVE) o tratamento em que as sementes foram submetidas à embebição por 48 horas e que se realizou o desponte no lado oposto ao embrião com auxilio de uma tesoura, obteve maior índice $(0,65)$ de sementes emergidas por dia, diferindo estatisticamente apenas do tratamento sementes intactas + 24 horas de embebição (Figura 2). Resultados contrários foram obtidos por Matos et al. (2003) trabalhando com quebra de dormência em sementes de Saputi (Achras sapota L.) com relação ao índice de velocidade de emergência, os menores valores foram obtidos quando se utilizou a escarificação com lixa $n^{\circ} 100$ seguida de embebição por 48 horas $(0,13)$, e a imersão em água a $70^{\circ} \mathrm{C}$ até resfriamento $(0,18)$. Portanto, não devem ser usados como tratamentos prégerminativos em sementes de saputi.

Quanto ao comprimento de raiz o tratamento que obteve melhor resultado foi 0 realizado com as sementes com desponte $(3,1)$, diferindo estatisticamente dos demais tratamentos. Diferente de Ferreira et al. (2009) trabalhando com superação de dormência em sementes de bibirá (Rollinia mucosa) com relação ao comprimento da

TABELA 1. Resumo da análise de variância para porcentagem de emergência (\%E), índice e velocidade de emergência (IVE), comprimento de raiz (CR), altura de plântulas (AP), e peso da massa seca (PMS), em função do desponte e embebição das sementes de noni.

\begin{tabular}{ccccccc}
\hline \multicolumn{7}{c}{ QM (Características) } \\
\hline Fonte de variação & GL & $\% \mathrm{E}$ & IVE & CR $(\mathrm{cm})$ & AP $(\mathrm{cm})$ & PMS (g) \\
Tratamentos & 9 & $347,11^{*}$ & $0,03^{*}$ & $0,33^{*}$ & $0,04^{*}$ & $0,003^{*}$ \\
Média & - & 66,0 & 0,53 & 2,47 & 1,50 & 0,128 \\
CV & - & 15,8 & 16,7 & 12,7 & 8,9 & 22,2 \\
\hline
\end{tabular}

* - Efeito significativo pelo teste de tukey ao nível de $5 \%$ de probabilidade

Fonte: Dados obtidos de pesquisa (2010)

Rev. Bras. Pl. Med., Botucatu, v.13, especial, p.513-517, 2011. 
TABELA2. Médias da porcentagem de emergência (\%E), índice e velocidade de emergência (IVE), comprimento de raiz $(C R)$, altura de plântulas (AP), e peso da massa seca (PMS), em função do desponte e embebição das sementes de noni.

\begin{tabular}{|c|c|c|c|c|c|}
\hline Tratamentos & $\mathrm{E} \%$ & IVE & $\mathrm{CR}(\mathrm{cm})$ & $\mathrm{AP}(\mathrm{cm})$ & PMS (g) \\
\hline Sementes intactas & $74,0 \mathrm{a}$ & $0,61 \mathrm{a}$ & $2,6 a b$ & $1,7 \mathrm{a}$ & $0,15 \mathrm{a}$ \\
\hline Desponte & $73,0 \mathrm{a}$ & $0,62 \mathrm{a}$ & $3,1 \mathrm{a}$ & $1,7 a b$ & $0,15 \mathrm{a}$ \\
\hline $\begin{array}{c}\text { Sementes intactas }+12 \mathrm{~h} \\
\text { de embebição }\end{array}$ & $66,0 a b$ & $0,57 \mathrm{a}$ & $2,4 a b$ & $1,6 a b$ & $0,13 \mathrm{a}$ \\
\hline $\begin{array}{c}\text { Sementes intactas }+24 \mathrm{~h} \\
\text { de embebição }\end{array}$ & $43,0 \mathrm{~b}$ & $0,33 \mathrm{~b}$ & $2,2 b$ & $1,4 a b$ & $0,06 \mathrm{~b}$ \\
\hline $\begin{array}{c}\text { Sementes intactas }+36 \mathrm{~h} \\
\text { de embebição }\end{array}$ & $67,0 a b$ & $0,55 a$ & $2,3 b$ & $1,5 a b$ & $0,11 \mathrm{ab}$ \\
\hline $\begin{array}{c}\text { Sementes intactas }+48 \mathrm{~h} \\
\text { de embebição }\end{array}$ & $68,0 \mathrm{a}$ & $0,53 \mathrm{ab}$ & $2,4 \mathrm{~b}$ & $1,4 a b$ & $0,14 \mathrm{a}$ \\
\hline $\begin{array}{l}\text { Desponte }+12 \mathrm{~h} \\
\text { de embebição }\end{array}$ & $65,0 \mathrm{ab}$ & $0,55 a$ & $2,5 a b$ & $1,3 \mathrm{~b}$ & $0,13 a$ \\
\hline $\begin{array}{l}\text { Desponte }+24 \mathrm{~h} \\
\text { de embebição }\end{array}$ & $64,0 a b$ & $0,46 \mathrm{ab}$ & $2,4 a b$ & $1,6 a b$ & $0,12 a b$ \\
\hline $\begin{array}{l}\text { Desponte }+36 \mathrm{~h} \\
\text { de embebição }\end{array}$ & $61,0 \mathrm{ab}$ & $0,47 \mathrm{ab}$ & $2,1 \mathrm{~b}$ & $1,4 a b$ & $0,12 \mathrm{ab}$ \\
\hline $\begin{array}{l}\text { Desponte }+48 \mathrm{~h} \\
\text { de embebição }\end{array}$ & $76,0 \mathrm{a}$ & $0,65 \mathrm{a}$ & $2,8 a b$ & $1,5 a b$ & $0,16 \mathrm{a}$ \\
\hline
\end{tabular}

Letras seguidas pela mesma letra na coluna não difere entre si pelo teste de tukey à $5 \%$ de probabilidade.

Fonte: Dados obtidos de pesquisa (2010)

raiz o tratamento que obteve melhor resultado foi o realizado com sementes escarificadas com lixa $\mathrm{N}^{\circ}$ 80 em um dos lados + embebição com água destilada durante 24 horas.

Quanto a altura de plântula o melhor tratamento foi a testemunha (sementes intactas), embora não tenha diferido do tratamento com desponte e este não tenha diferido dos demais. Mendonça et al. (2007), obteve maiores alturas de plântulas de gravioleira quando realizou o desponte em sementes de gravioleira.

Em se tratando do peso de massa seca o melhor tratamento foi o de sementes com desponte e 48 horas de embebição $(0,1627)$; mesmo assim não diferiu estatisticamente dos seguintes tratamentos:aqueles onde se realizou apenas 0 desponte, a testemunha, as sementes intactas com 48 horas de embebição, o desponte com 12 horas de embebição e as sementes intactas com 12 horas de embebição. Diferente de Ferreira et al. (2009) trabalhando com superação de dormência em sementes de bibirá (Rollinia mucosa), o tratamento que obteve melhor resultado foi o realizado com sementes escarificadas com lixa $N^{\circ} 80$ em um dos lados e embebição com água destilada durante 24 horas.

\section{CONCLUSÃO}

Embora não tenha diferido da testemunha, o tratamento desponte +48 horas de embebição mostrou-se ser o mais eficiente para acelerar a emergência das plântulas.

\section{REFERÊNCIA}

BRITO, D.R.B. Avaliação da atividade anti-helmíntica da Morinda citrifolia (noni), em aves poedeiras naturalmente infectadas. 2008. 62f. Dissertação (Mestrado em Ciência Animal) - Universidade Federal do Piauí.

CARMO FILHO, F.; ESPÍNOLA SOBRINHO, J.; AMORIM, A. P. Dados meteorológicos de Mossoró: janeiro de 1898 a dezembro de 1986. Mossoró: ESAM/FGD, 1987. 325p.

CARVALHO, M. de C.; NAKAGAWA, J. Sementes: ciência, tecnologia e produção. 4. ed. Jaboticabal: Funep, 2000. $588 \mathrm{p}$.

ELKINS, R. Noni (Morinda citrifolia) la hierba preciada del pacífico sur. Woodland Publishing. Pleasant Grove, UT. 31 p. 1997.

FANTI, S. C.; PEREZ, S. C. J. G. de A. Efeito do estresse hídrico e envelhecimento precoce na viabilidade de sementes osmocondicionadas de paineira (Chorisia speciosa). Pesquisa Agropecuária Brasileira, Brasília, 
v. 38, n. 4, p. 537-543, 2003.

FERREIRA, D. F. Análise estatística por meio do SISVAR (Sistema para Análise de Variância) para Windows versão 4.0. In: REUNIÃOANUAL DAREGIÃO BRASILEIRA DA SOCIEDADE INTERNACIONAL DE BIOMETRIA, 45., 2000, São Carlos. Anais... São Carlos: UFSCar, p. 255258, 2000.

FERREIRA, M. G. R.; SANTOS, M. R. A.; SILVA, E. O.; GONÇALVES, E. P.; ALVES, E. U.; BRUNO, R. L. A. Superação de dormência em sementes de biribá (Rollinia mucosa (Jacq.) Baill). Revista brasileira sementes, Londrina, v. 31, n. 4, 2009.

GERMOSÉN-ROBINEAU, L. Hacia uma farmacopea caribanã. 7. ed. Santo Domingo: Tramil, 1995. 696p. HENCKEL, P. A. Fisiología de la resistencia de las plantas al calor y a la sequía. Moscou: Nauka, 1982. 280 p. HEYDECKER, W.; HIGGINS, J.; GULLIVER, Y. R. Accelerated germination by osmotic seed treatment. Nature, v. 246, p. 42-44, 1973.

HEYDECKER, W.; HIGGINS, J.; TURNER, Y. J. Invigoration of seeds? Seed Science and Technology, v. 3, p. 881888, 1975.
KHAN, A. A.; TAO, K. .L.; KNYPL, J. R.; BORKOWSKI, B.; POWELL, L. E. Osmotic conditioning of seeds: physiological and biochemical changes. Acta Horticulturae, v. 83, p. 267-278, 1978. MATOS, V. P.; AZEREDO, G. A.; GONÇALVES, E. P.; SILVA, A.; RODRIGUES, L. F.; Sementes de sapoti (Achras sapota L.): dormência e emergência. Pesquisa Agropecuária Tropical, v.33, n.2, p.79-82, 2003. MENDONÇA. V.; RAMOS. J. D.; PIO. R.; GONTIJP. T. C. A.; TOSTA. M. S.; Superação de dormência e profundidade de semeadura de sementes de gravioleira. Revista caatinga, v.20, n.2, p. 73-78, 2007.

POPINIGIS, F. Fisiologia da semente. 2. ed. Brasília: [s. n.], 1985.298 p.

RODRÍGUEZ, F. J. M; PINEDO, D. M. [Online]. Mito y realidad de Morinda citrifolia L. (noni).2005. Disponível em: < http://www.bvs.sld.cu/revistas/pla/vo19_3_04/ pla02304.htm. Acesso em: 10 set 2010.

XANGAI, J. [Online]. Fruto típico da Ásia já pode ser encontrado em Rio Branco. 2007. Disponível em: < http:/ / w w w 2.uol.com . br/pagina $20 / 28012007$ / c_0428012007.htm. Acesso em: 17 set. 2010. 